\title{
Ethical leadership: Exploring bottom-line mentality and trust perceptions of employees on middle-level managers
}

\author{
Mehreen Malik $^{1} \cdot$ Farah Mahmood $^{1} \cdot$ Naukhez Sarwar $^{1} \cdot$ Asfia Obaid $^{1} \cdot$ Mumtaz Ali Memon $^{1}$ (D) Asadullah Khaskheli $^{2}$
}

Accepted: 15 February 2022

(c) The Author(s), under exclusive licence to Springer Science+Business Media, LLC, part of Springer Nature 2022

\begin{abstract}
With the increased competitiveness and significance of the workforce, the responsibility of organizational leaders has been increased to behave ethically and lead their followers in the best ethical way. This study aims to explore how the perception and trust of followers of their middle-level managers can shape the ethical behavior of middle managers and their bottom-line mentality. This qualitative study was conducted using semi-structured interviews from 10 employees of two Pakistani textile organizations-selecting five employees from each. Thematic analysis was used for data analysis. The findings reported that the bottom-line mentality demands are given priority. Thus, to achieve these demands, ethical values are being ignored while the nature of the task and attitude of the supervisor leads towards the social undermining of the employees. Furthermore, it has been found that leaders' behavior and personality are more important in building trust and perception of employees, and this perception does not entail that leader will be acting ethically in real, but they are perceived to be. This study can provide valuable implications for policymakers, especially HR personnel, to device policies by considering ethical leadership practices. The findings of this research recommend that better performance and profit maximization by employees can be enhanced by reducing the bottom-line mentality of top management. Few scholars have elaborated on ethical leadership, the complexity of the leader-follower relationship, and individual perceptions. Behavioral aspects, bottom-line mentality, and trust from employees' perspective in ethical leadership have received little attention. In addition, this research has taken a step forward by exploring the collectivist country of Pakistan.
\end{abstract}

Keywords Ethical leadership $\cdot$ Bottom line mentality $\cdot$ Trust $\cdot$ Social undermining

Mumtaz Ali Memon

mumtazutp@gmail.com

Mehreen Malik

mehreen.phd20nbs@student.nust.edu.pk

Farah Mahmood

farah.phd20nbs@ student.nust.edu.pk

Naukhez Sarwar

naukhez.sarwar@nbs.nust.edu.pk

Asfia Obaid

asfia.obaid@nbs.nust.edu.pk

Asadullah Khaskheli

asadullahkhas@hotmail.co

1 Department of Management \& HR, NUST Business School, National University of Sciences and Technology (NUST), Islamabad, Pakistan

2 School of Management, Hainan University, Haikou, People's Republic of China

\section{Introduction}

Ethical leadership has gained special attention from scholars and researchers during the last decade (Banks et al., 2021). Such ethical practices are important for both local and global organizations. Additionally, moral values are crucial to keep employees committed and to survive in the competitive market (Bahadori et al., 2021). As working conditions have been continuously evolving with more significance to team structure and collective task achievement, therefore, ethical forms of leadership are of great significance.

Employing ethical leadership practices in the workplace not only reduces discretionary behavior Van \& Hogg (2017), but it also encourages employees to act morally and positively in the workplace (Mo \& Shi, 2017). Ethical behavior is usually expected from the top management, who are the role models and influencers for their followers to behave ethically (Greenbaum et al., 2020). 
There has been a constant interest by researchers in studying leadership behaviors and their impact on employees' task performance and overall organizational performance (Lemoine et al., 2019). However, the interest was initially in leaders only, how they behave, and what characteristics and qualities they possess that result in effective leadership behavior (Peng \& Kim, 2020). Later, researchers included followers' perspectives to have an impact on how ethical leaders emerge, behave and influence others to exhibit ethical behavior. Literature highlights three main aspects in which followers' behavior in relation to their leaders are studied: personal beliefs, values and characteristics of followers, varied job-related experiences of different followers, and how followers perceive their leaders (Chong \& Wolf, 2010).

Moreover, employees' perception of trust in their supervisors and leaders may influence leaders' actions to behave in more moral and ethical manners (Solinger et al., 2020). Trust is the psychological state in which employees develop positive intentions towards their team leaders (Rousseau et al., 1998; Yang \& Mossholder, 2010). Leaders play a significant role in employees' work behavior; how they behave and act in achieving organizational goals (Burke et al., 2007). Employees develop a relationship of mutual trust with leaders who act and behave ethically towards them. This, consequently, builds the leader-member relationship among the employees and team leaders (Blau, 1964). As per the findings of earlier studies by Kalshoven et al. (2011) and Simons (2002) employees' perception of the ethical leadership practices of their leaders contributed significantly towards building their trust in them (leaders). Additionally, Bandura and Walters (1977; Bandura 1986) and Brown et al. (2005) have found that employees are more attracted towards trustworthy and ethically behaving leaders. Taking these findings together, this research has studied employees' trust perception of their ethical leaders to develop a theoretical explanation of the emergence and exhibition of ethical leadership in middle-level managers or direct supervisors. It is essential to study because it can be viewed as a process explaining the critical relationship between leaders and followers (Gottfredson et al., 2020). The theoretical literature clearly shifts the focus from individual leaders to followers as well who equally and actively participate in the executive leadership behaviors by organizational leaders (Andersen et al., 2020).

The emerging body of literature has highlighted the significance of exploring the bottom-line mentality from different angles of leadership styles (Greenbaum et al., 2012; Mawritz et al., 2017; Mesdaghinia et al., 2019). The employees working in the bottom-line mentality environment are primarily focused on achieving the goals, and in such an environment, the win of one is the loss of another (Greenbaum et al., 2012; Wolfe, 1988). As a result, such environments create competition among coworkers, which reduces concern for others working around them (e.g., Gasiorowska et al., 2016). As a result, such a bottom-line mentality leads towards the social undermining of employees, which is the fulfillment of demands at the expense of ethics (Shepard, 1965). Such an attitude of supervisors hinders them from paying attention to the employees working around them (e.g., Molinsky et al., 2012; Sirola \& Pitesa, 2017). In such environments, it is unlikely that supervisors will act ethically towards their employees (e.g., Li, 2013; Mahsud et al., 2010), which leads towards the social undermining of employees.

Supervisors, who act ethically, provide support to people working around them in such environments through their fair and equitable decisions (Brown et al., 2005). Ethical leaders practice fair standards through discipline and communication among their team members. As suggested by arguments related to ethical leadership practices and social undermining, employees' well-being is related to the attitude of supervisors (Henderson \& Argyle, 1986). Leaders who follow ethics build social relationships with their employees. Based on the theoretical grounding of social rules theory (SRT), the social undermining of employees restricts the effectiveness of ethical leadership (Mostafa et al., 2020). In ethical leadership, the leader-follower relationship is maintained through rewards and punishments of the culprits (Brown \& Treviño, 2006). Theoretically, in ethical leadership, the good attitude of the leader and clearly defined tasks reduce the likelihood of social undermining of the employees (Mostafa et al., 2020). Thus, we have advanced the literature by arguing that that the bottom-line mentality demands are given priority and to achieve these demands, ethical values are being ignored. The two variables, namely the nature of the task and attitude of the supervisor, emerged from the data collection and analysis which reported that the nature of the task and attitude of the supervisor lead towards the social undermining of the employees. Practically, it is also significant for organizations to be aware of social undermining of employees in ethical leadership practices in the workplace.

As ethical leadership has not taken individual perceptions into account to determine the complexity of the leader-follower relationship, therefore, more research is needed to explore the behavioral aspects of employees, trust perceptions, and bottom-line mentality (Greenbaum et al., 2020; Solinger et al., 2020). Therefore, the objectives of this research are three-fold. Firstly, to identify the trust and perception of followers toward their middle-level managers and immediate supervisors. Secondly, to explore the perception and trust of followers to motivate their leader's genesis of ethical leadership. Thirdly, to identify the perceptions of top management BLM (bottom line mentality) leading to the social undermining of middle-level managers in the genesis of ethical leadership. The fulfilment of these objectives will cover the gaps in the literature. 
Therefore, the present study attempts to explore the ethical leadership, trust perception, and bottom-line mentality of middle-level managers and the role of top management. To fulfil the objectives of this research and to cover the gaps in the literature, this research has studied the following research questions:

RQ1: How do trust and perception of followers by their middle-level managers and immediate supervisors motivate leaders in the genesis of ethical leadership?

RQ2: How do the perceptions of top management's bottom line mentality lead to the social undermining of middle-level managers in the genesis of ethical leadership?

In designing this research, the prime focus was on two issues. The first issue focuses on the perception of followers of their (immediate supervisors) leaders and trust, which needs to be explored (Solinger et al., 2020). The present research is filling the gap by conducting it in the Asian context, as the extant literature shows that most studies have been undertaken in China (Babalola et al., 2020; Greenbaum et al., 2020). USA (Marquardt et al., 2020; Zhu et al., 2019). Thus, most of the research related to trust perception of followers and ethical leadership has been conducted on developed countries' employees, especially western countries (Le \& Tran, 2020). Therefore, it would be interesting to understand how ethical leaders behave in an Asian context in which there are varied cultural norms and organizational environments. Countries such as Pakistan are collectivist societies, and it has been suggested that ethical leadership needs to be explored in collectivist countries (Solinger et al., 2020).

The second key issue focuses on the Bottom-Line Mentality (referred to as BLM) and social undermining of employees. In this stream, mid-level as well as lower-level managers have been greatly ignored while studying ethical leadership. Therefore, it would be significant to study the role of midlevel managers in ethical leadership behavior since they are a great influence on employees within organizational settings. Leadership studies have been done with a particular focus on CEOs' ethical practices in organizations (Maak et al., 2016) but not from the perspective of middle-level managers.

\section{Literature Review}

\section{Ethical Leadership}

Brown and Treviño (2006) and Brown et al. (2005) have defined ethical leadership as the demonstration of normatively appropriate conduct through personal actions and interpersonal relationships and the promotion of such conduct to followers through two-way communication, reinforcement, and decision-making. The concept of ethical leadership is grounded by Brown et al. (2005) in social learning theory (Bandura, 1986). According to this theory, people learn by observing how others, especially role models like teachers, leaders, and parents, behave. Likewise, the employees learn ethical conduct in the organizations by observing their leaders and how ethically they behave. Ethical leaders are trustworthy, respect everyone, treat everyone equally in the organization, do not show favoritism, and carry out their duties ethically and responsibly (Treviño et al., 2006). Ethical leaders are the role models and mentors who are in powerful positions in the organization and can capture the attention of their subordinates through their charismatic personalities. It has been highlighted that leader behave differently with different subordinates based on the perception of them in a dyadic relationship. Therefore, it can be argued that those followers who perceive and trust their leaders to be ethically sound would get a positive reaction from their leaders because of the social exchange. In the past few decades, ethical leadership has been studied widely. Studies have highlighted that the role of a leader has a significant impact on the ethical conduct of business (Zhu et al., 2019). Top management and supervisors with ethical values provide support to their followers and display their ethical leadership practices by making transparent, fair decisions, always willing to support and help people around them (Piccolo et al., 2010).

\section{Leader Member Exchange (LMX) Theory}

The holistic approach to studying the quality of relationships among leaders and followers is the LMX theory. The main aspect of the study is the interaction of both leaders and followers in this theory (Buengeler et al., 2021). The quality of this relationship is an important predictor of task meaningfulness and for social aspects related to followers, such as information access, status differences, leaders' attention, and level of autonomy in performing the tasks and duties (Gottfredson et al., 2020). The interesting proposition of LMX is that there exists a distinct relationship of a leader with each of the followers (Aggarwal et al., 2020). It has been highlighted that leader tend to foster relationships with their followers, characterized by trust, social exchange, and a sense of being liked and respected by their followers (Buengeler et al., 2021). Leaders would be distant from the ones contrary to these attributes. Therefore, it can be proposed that ethical leadership would be a by-product of LMX in which followers would tend to invest in the form of trust and a positive perception of their leaders, while leaders, on the other hand, will exhibit ethical leadership as a social exchange.

Another perspective of the trust foundation is the emotional bond between the trustor and the trustee (Byun 
et al., 2017). This relates to trust's intrinsic virtue that a person believes in a relationship and, hence, is emotionally invested in that relationship by exhibiting special care and sincere concern for others (Chen \& Lin, 2018). Consequently, these emotional ties then bind the individuals by building a positive sense of the relationship. At the organizational level, there are exchange relationships which are governed or influenced by these trust ties. One such relationship could be LMX (Yu et al., 2018). The quality of the relationship is enhanced if one party receives more resources than they give (Valle et al., 2019). Therefore, it can be proposed that if mutual trust is higher in LMX, the quality of the relationship will be better as there may be more loyalty and resources among leaders and members. Research has tried to establish the linkage between members' perceptions of trust and the actual trust level of their leader (Herman et al., 2018). Hence, the research signifies the importance of members' perceived trust as an antecedent of the LMX relationship. On the other hand, researchers have also emphasized that both the constructs "members' trust in the leader" and "leader's trust in members" are not the same (Gaudet \& Tremblay, 2017). Leaders exist at a higher hierarchical level within organizations and have the capability of influencing followers in a significant manner. Therefore, their interactions with their followers are more likely to be shaped by their trust in their members. This leader's trust in their members does not only instigate members' trust levels in their leader but can also significantly influence their exchange relationships as well as LMX (Byun et al., 2017). LMX research is based on the notion of social exchange theory that there occurs an exchange of different resources among leaders and members, largely impacting the quality of their relationship (Lloyd et al., 2017). One of the important factors in building followers' perception is the leader's behavior. For example, rewards, leaders' feedback, and their support to encourage their members' success enhance the quality of their LMX relationship (Dulebohn et al., 2012). However, it is also important to note that these contingent rewards, as well as the support they provide, depend on the leader's trust at a certain level in their members. Therefore, the leader's trust seems to be present at a fundamental level in the LMX relationship compared to other factors, and it has the tendency to impact the dynamics of the leadermember. A leader's trust can be effect-based as well as based on cognition. At the beginning of LMX interactions, affect appears to be more important than other elements (Herman et al., 2018). This implies that if a leader has a natural tendency to trust their members, it could help overcome various issues pertaining to insufficient information about the benevolence of their members and their integrity. Consequently, the initiation of dynamics and workflow processes between two parties can be quicker.

\section{Perception and Trust of Followers}

Conventionally, trust is perceived to be a belief, positive expectations, or any positive intentions in the form of a psychological condition that further provides a basis for the social behavior of human beings (Lusher et al., 2012). Although trust cannot be explicitly monitored or exists tacitly, it enables people to trust and follow non-contractual obligations, and people usually become vulnerable knowingly (Setyaningrum et al., 2020). Trust is interwoven so finely into workplace day-to-day operations that it is normally studied just like any other organizing principle within organizations. For example, contractual relations could be governed by basing perceived trust as a general system. Another most important application of perception of trust is that it controls opportunism and monitoring issues can also be alleviated. Therefore, when employees perceive that their leaders are trustworthy and follow ethical and moral behavior, they will follow their supervisors. From the perspective of employees' trust in leadership depends on the leaders' care and concerns for others. According to Prastio et al. (2020), trust in leaders has two types: reliance-based trust, which is defined as an individual's readiness to place reliance on the work-related skills, abilities, and knowledge of another; and disclosure-based trust, which is described as an individual's willingness to disclose work-related sensitive aspects or personal opinions and information to another. When followers trust their leaders, it will entail a positive sense within the leaders themselves, and therefore, they will emerge as fairer and transparent in assigning as well as evaluating the duties of their subordinates.

\section{Bottom Line Mentality}

The bottom-line mentality is still at its fancy, and there is a need to explore this construct in various organizational settings. The bottom line is often cited in terms of financial gains and profits, but generally, it is defined as whatever "is worth paying attention to while everything else is discarded" (Wolfe, 1988). This term is interpreted as something related to profits, but BLM mostly aligns with Wolfe's definition, which explains that the employees' primary focus is on factors that are of particular importance while belittling the importance of other things (Greenbaum et al., 2012). Giving due importance to certain bottom-line outcomes is often believed to be profitable for the organization, Trevio et al. (2006). Still, according to Greenbaum et al. (2012), when the top management's primary focus lies in achieving the bottom-line goals of the organization, they often ignore the employees. They do not treat them fairly, and employees are focused on meeting the bottom-line demands, ignoring the ethical consequences of their behaviors. In today's business environment, the bottom-line mentality is increasing; 
however, its consequences on leader-follower relationships are yet to be studied (Greenbaum et al., 2020). It is important to study how this bottom-line mentality would discourage middle-line managers and they would be having a negative consequence on followers' perception of them.

\section{Bottom-Line Mentality and Social Undermining}

According to Wolfe (1988), BLM can result in conflict among the employees and management of the organization. Top management, with the aim of achieving bottom-line demands, is just focused on profits, and they disregard the success of others in the organization. It is believed that whoever contributes more towards the bottom-line goals will be the winner. As a result of this, the employees compete rather than cooperate. As articulated by Wolfe (1988), employees with this one-dimensional thinking of bottom-line goals are "a short step away from wanting others to fail to actually help them fail by undermining their efforts, withholding information, or making them look bad". It can be concluded here that the bottom-line goals of the organization are being met at the expense of other employees working within the same organization (Sims \& Brinkman, 2002). According to Greenbaum et al. (2012) the success of employees is intentionally hindered by the top management, which leads to social undermining (e.g., providing the wrong information, competition for status and delaying the work, etc.). As per the literature, such practices of management are harmful to the proper functioning of the organization (Greenbaum et al., 2012). Ethical leadership should come into practice to reduce the social undermining of employees, and the role of middle management is important.

In literature, the role of middle-level management is given due importance as the middle-level managers are the middle layers of the organization, and they are responsible for the implementation of actions, processes, and communication between the top management and front-line managers (Singh et al., 2020). The managers' characteristics influence moving the organization towards ethical conduct as they work as a bridge between the top management teams and the lowerlevel managers. Therefore, to minimize the hierarchical gap and reduce the social undermining of employees, this research highlighted the role of middle managers, who, by acting ethically and morally, can help employees reduce their social undermining.

\section{Methods}

We have used a qualitative research approach to develop an in-depth understanding of the two research questions of this research, i.e., how trust and perception of followers by their middle-level managers and immediate supervisors motivate leaders in the genesis of ethical leadership and how the perceptions of top management's bottom-line mentality led to the social undermining of middle-level managers in the genesis of ethical leadership. Majority of the studies on ethical leadership have been carried out using quantitative research approach (Ahn et al., 2018; Babalola et al., 2019; Cheng et al., 2019; Zoghbi-Manrique-de-Lara \& Viera-Armas, 2019), therefore, it becomes important to study ethical leadership qualitatively. The data was collected through semistructured interviews which is one of the renowned methods to collect data in qualitative studies (Creswell, 2003). We conducted interviews using non-standardized, telephonic one-to-one interviews (Mark et al., 2009). The telephonic one-to-one interviews were conducted due to COVID-19 restrictions. The participants were from the labor-intensive sector of Pakistan. They were difficult to reach through online platforms due to the unavailability of the Internet.

\section{Research Philosophy and Research Approach}

The philosophical underpinning of this research lies in constructivism (Creswell, 2003). According to Creswell (2003), in this worldview, the researchers follow the subjective meaning of the objects. This study involves trust perceptions, bottom-line mentality, and its relationship with leadership behavior which is subjective in nature. To align with the objectives of this study, the research approach adopted is phenomenology. In this approach, the lived experiences of the participants are analyzed through thematic analysis (Hayllar \& Griffin, 2005). The participants' lived experiences of the ethical conduct by their organization were interviewed to gain an in-depth knowledge of the phenomenon.

As per literature, most of the studies on ethical leadership have been carried out using a quantitative research approach (Babalola et al., 2020; Greenbaum et al., 2020), and this study aims to study the perception of trust of followers, bottom-line mentality, and ethical leadership. Therefore, an inductive approach (qualitative lens) is adopted consistent with the explanation of Saunders et al. (2009).

\section{Participants}

The respondents were selected using the purposive sampling technique. This technique is chosen to select the right population which falls within the scope of research aims and objectives of the study (Saunders et al., 2009). The study has employed this sampling technique to target the employees of two private textile organizations of Pakistan.

Interviewees were from the two private textile organizations of Pakistan. The prime focus was on the textile industry of Pakistan because it is one of the main sources of exports for Pakistan (Khan \& Khan, 2010), It is the low wage sector which plays a big role in the economic development of 
Pakistan. The majority of the labor force works in the core industry of Pakistan. The bottom-line demands are fulfilled at the cost of intensive labour work, specifically in the production department, which is responsible for meeting the demands, and the service department, which is responsible for the in-time delivery of products and services. In laborintensive industries, middle managers and immediate supervisors serve as a link between upper and lower management in order to implement production demands.

The Pakistani textile industry is the core industry (Khan $\&$ Khan, 2010). The textile sector of Pakistan is the valueadded chain, and there are subsectors of each sector. The product of one sub-sector is the raw material for the other sector in line. The final product of the textile industry-in the form of a garment-starts with the picking of cotton and involves the value-added processes of spinning, weaving, and dying to make it a final product. Each step is labourintensive and offers employment opportunities to the masses of Pakistan. As it is a labour-intensive industry and core industry of Pakistan, it was best suited for data collection and to have in-depth knowledge of ethical leadership conduct from their perspective. The participants were from both the production and services departments.

We determined the sample size by using information power approach. In most qualitative research, the sample size is determined based on the saturation point (Saunders et al., 2009). The researcher in the saturation point approach stops looking for additional information when no new themes emerge (Bougie \& Sekaran, 2016). Therefore, to determine the accurate sample size, the authors of this research have adopted the information power approach (Malterud et al., 2016).

Information power explains that "the more information the sample holds, relevant for the actual study, the lower number of participants is needed"(Malterud et al., 2016).
Information power guides the researcher to determine the sample size on the basis of five items: "(a) study aim, (b) sample specificity, (c) use of established theory, (d) quality of dialogue, and (e) analysis strategy" (Malterud et al., 2016). Using the guidelines of information power, we conducted 10 interviews with the participants. The quality of dialogue with the participants was strong and clear. Additionally, the characteristics of participants were highly qualified according to the aims and objectives of the study. The LMX supported the study, and having theoretical support requires less sample size. In this exploratory study, the analysis strategy was not cross-sectional; only a single case phenomenon of ethical leadership was considered. The summary of the participants' demographic data showed that most of the participants were male (see Table ).

\section{Data Collection}

Prior to the interview, the participants were asked to arrange a phone call in a quiet and calm place on the telephone. The interview time was also decided in advance as per the convenience of the participants. A semi-structured interview format was adopted. The interview guide and protocol were prepared. Two full-fledged pilot interviews were conducted with the targeted participants. The interview questions and wording were revised on the basis of participants' feedback. The prime data was collected on the revised interview guide (see Table 1) and the consent of the participants was taken before the start of the interview.

The interview guide was divided into three sections. In the first section, the participants were introduced to the project. There were closed and open-ended questions on the Bottom-Line Mentality, Social Undermining, ethical leadership, and trust in the second section. The last section contained the closing of the interview, and the further

Table 1 Research instrument details

Research Question

Bottom Line Mentality

1. Can you please talk about your top management role in achieving bottom line demands?

2. How much your management follow ethics in meeting BLM?

3. Do you think your management treat you ethically?

4. How do you perceive your supervisor's role in dealing with you?

5. What is the role of middle managers in your organization in operationalization of ethics?

Social Undermining

1. Can you please tell that when your management is completely focused on achieving bottom line outcomes?

2. Can you please tell how BLM leads you towards social undermining?

Ethical leadership

1. Can you please tell your stance on ethical leadership?

2. Can you please tell that the decisions made by your management are fair?

3. Do you think your management act ethically?

4. Do you managers help employees in meeting the goals?

5. Do they keep the interest of you and other employees in mind?

Trust

1. Can you please tell how much do you trust your management decision?

2. Can you please tell do your trust on management motivate you to perform ethically? 
usage of data was explained, and the participant's consent for the publication of results was ensured. The interview was organized around these issues, but further questions were asked for clarification and the generation of new themes. We recorded the interview, and the participant's consent was obtained for the recording. The interviews ranged from 15 to $30 \mathrm{~min}$, depending on the availability and schedule of the participant (Table 2).

\section{Data Analysis Strategy}

Following the interviews, each interview was transcribed and coded manually. The three approaches of Van Manen (1990) were used for the thematic analysis of data. First, the definitions and themes of each construct were developed. Second, the themes and definitions were reviewed again by both researchers for accuracy. Thirdly, the themes were confirmed for reliability purposes. After the detailed thematic analysis, the description Moustakas (1994) was prepared to combine the common themes and experiences. Finally, the more repetitive themes were considered, which explained the phenomenon's essence in the best possible way. For the data analysis, the participants were assigned anonymous names to maintain their confidentiality. Direct quotes were used in italics in the main text of the article.

\section{Thematic Analysis}

This study has followed a systematic approach to generate themes. It started with the identification of themes based on the codes, then we analyzed the themes and described them based on analysis. The two broad themes, i.e., bottom-line mentality and perception and trust of employees, emerged. The sub-themes have depicted the nature of the task, which has two further sub-themes: easy task nature and the difficult nature of the task. The easy nature of the task leads towards the good attitude of the supervisor, while the difficult nature of the task leads towards the bad attitude of the supervisor. In contrast, the bad attitude led to social undermining. Four sub-themes emerged out of the perception and trust of employees: the leader's personality, perception of SOP's, work pressure, and abusive behavior.

\section{Results}

We derived the initial 50 codes, which were summarized in sub-codes, further refined into three categories. The schematic analysis revealed the perceptions regarding the nature of tasks of top management BLM (bottom line mentality) leads to the social undermining thus the ignorance of ethical leadership. Ethical leadership is being studied under the main four categories: bottom-line mentality, social undermining, and bottom-line mentality, trust, and ethical leadership. The findings of each are discussed as follows:

\section{Ethical Leadership-Followers' Perception and Trust}

The first concern of this study was to identify if the leaders are behaving ethically overall. Before asking direct questions, informants' knowledge about ethical behavior was checked. We got the initial understanding that by ethics, they had the preconception that it is related to something harassment and abusive behavior to be very specific.

\section{Abusive Behavior}

The majority of the informants have reported that abusive behavior and bullying are very common when it comes to the interaction of supervisors with their floor workers. The participants have reported that abusive behavior is more
Table 2 Demographics of the participants

\begin{tabular}{llllll}
\hline No & Name & Gender & Qualification & Position & $\begin{array}{l}\text { Experi- } \\
\text { ence } \\
\text { (years) }\end{array}$ \\
\hline 1 & A & M & MBA & HR Deputy Manager & 4 \\
2 & B & M & Bachelors & HR assistant & 7 \\
3 & C & F & MBA & HR officer & 3.5 \\
4 & D & M & Master's in computer science & Techno Functional Analyst & 6 \\
5 & E & M & Bachelors & Maintenance Supervisor & 3 \\
6 & F & M & Bachelors in Textile Engineering & DSM & 4.5 \\
7 & G & M & Bachelor's in commerce & Accounts Officer & 6 \\
8 & H & M & Master's & Admin Executive & 2 \\
9 & I & M & Bachelor's Business Admin & HR Officer & 2 \\
10 & J & M & Bachelor's & AM IT & 7 \\
\hline
\end{tabular}

F; Female, M; Male. To keep the data of participants confidential, all names are anonymous 
common in the production departments than in the services departments.

\section{E: You know that most of the people here are illiterate in the textile industry, and their language is foul; they tend to abuse people. I have been through all this.}

Similarly, it was also highlighted by more than half of informants that this unethical, abusive behavior comes from the head of the department that if he abuses then it will be directly trickling down the middle managers and they would behave unethically and vice versa.

\section{F: I can say from my experience that if your Head of Department (HOD) is corrupt and abuses people and misbehaves with their subordinates, it will automati- cally trickle down to us, and we would be behaving in the same manner with our workers.}

However, the findings become interestingly contradictory when the informants reported that their top management (company directors), on the other hand, are ethically good, and they praised them. They reported that they had been concerned for workers' wellbeing, and most of the department managers and heads are not reflecting on their own seniors' behavior and practices. This raises the question that if companies' owners and directors exhibit ethical leadership, it has no reflection on Managers and department heads who are directly reporting to them.

\section{Leader's Personality}

To get a bigger and clearer picture of followers' perception and ethical leadership, we collected data from different departments, which included services departments such as HR, and workers such as Spinning, Weaving, and packaging. 4 out of 10 indicated and reported that because of their Head of Department's good nature and ethical behavior managers in their department behave ethically. This highlights that perception of employees is built on leaders' personality if they would be behaving ethically. For example, if they are not abusing, the followers perceive that they behave ethically and follow all the ethical standards. Respondents also indicated that only it happens very rare in the textile industry that managers behave ethically and that too in case if the head of department is good himself.

F: If you ask about my views, I think I have been fortunate overall here. In terms of my boss, you must have heard that people do not change the jobs, they change boss.

Similarly, it was also mentioned by one of the informants that their previous head of department was corrupt. Therefore, they had to suffer a lot when it comes to annual increments and performance evaluations. However, with this new head of department, things have started changing, and now there is a clear improvement. Even if they couldn't get things right, they at least try to pitch it in front of top management and get it resolved.

G: I had been given very less increment previously because our previous manager never cared for our concerns, but now things are slightly better with the new Head of Department. They listen to us and promise that if they will compensate us in the next increment.

A critical analysis of findings indicates that leaders' individual behaviors and personalities create a strong perception of their followers, and they perceive them to behave ethically. However, the assumption that followers' perception about their leaders would result in leaders automatically behaving ethically is not clarified.

\section{Followers' Perception about SOPs}

While probing the informants about the adherence to Standard Operating Procedures (SOPs), around $80 \%$ of participants mentioned that there are no clearly defined SOPs. When it comes to performance evaluations, no KPIs are defined beforehand. They have been assigned tasks without getting their interest into account. Although $20 \%$ of the respondents mentioned that they always accept any kind of tasks for their personal growth and learning. However, no one reported that before assigning any task, any procedure is followed. This becomes problematic in cases where subordinates believe that their supervisors are unfair. As one of the respondents reported:

H: Last year, I was promoted to being Admin Executive, but surprisingly my manager called me in his office, and while breaking the news that although you do not deserve this promotion but still, I have given it to you. This was discouraging for me and heartbroken as well.

$H$ : There were no KPIs set for us, we never get to know what are the performance standards that we need to follow.

However, respondents of the department, whose head of department is considered to have a good persona, reported that all the SOPs have been following by the workers and staff members. This indicates a very strong impact of followers' perception of their leaders that in the absence of SOPs, the employees think that everything is going fine and there is adherence to company SOPs.

We always reach at 8:00 am, although our shift starts at 8:30 am. When we come to the office, our workers 
have already started their work, and we do not need to keep check and balance if anything.

\section{Work Pressure}

Another important theme that emerged out of data was work pressure. Due to manufacturing intensive nature, workers are required to increase efficiency and meet the targets set by top management. It was reported that top management is only concerned about the fulfillment of targets. It is the pressure of work that makes supervisors and managers only concerned about completing targets, whether behaving ethically or unethically.

E: I do not think there is any role of our directors in making supervisors behave more ethically as they are only concerned about the production. If the requirements and targets are met, but they do not care how these have been achieved. I think the main reason is because of lack of communication.

Similarly, informants of the department with ethically good HOD informed that they are given freehand and flexibility to accomplish their tasks. Hence, this can also be another reason that middle managers feel no desire to pressurize their subordinates and get the work done.

\section{$F$ : Another important thing is that there are many ups} and downs, but he has never passed it down to our level.

Therefore, from the analysis of findings, it can be inferred that perception about the work pressure also has an impact on leaders behaving ethically. When the work pressure increases and deadlines are approaching, managers and supervisors are only concerned about the fulfillment of tasks, and they get it done without taking care of ethical standards. Employees are assigned tasks randomly and are not given any choice, or their interests are not considered. They are assigned the tasks, and they are required to deliver on them.

\section{Bottom Line Mentality}

More than two-thirds of the interviews revealed the bottomline mentality of their supervisors or head of departments under which they work or operate the functions of the organizations. The overall analysis of the codes revealed the one main theme of the nature of work. The following quotes described this clearly:

A: Supervisor treats well. As a friend. But they are bound to HOD. Can sometimes do injustice. Depends on the nature of the task. They have pressure from HOD. As a private organization, the supervisor must follow the HOD at the end of the day. Being an employee, we must follow the orders and complete the tasks without considering the ethical or unethical issues.

$C:$ Depends on the nature of the task. Sometimes for some tasks, the time is limited, so high pressure, over time, and extended working hours. Sometimes a task is flexible. The behavior of management is also flexible.

The analysis of results revealed that around $90 \%$ of participants highlighted that the nature of the task to achieve bottom-line demands plays a vital role in the ethical behavior of the supervisor. If the nature of the task is flexible, the management also treats the employees with good behavior and follows ethics. On the other hand, if there are some difficult tasks and pressure from the top management, then the supervisor treats the employees unethically to meet the bottom-line demands assigned to them by the top management.

\section{Bottom Line Mentality and Social Undermining}

The social undermining is highlighted through the analysis of the data collected. The social undermining is linked with the bottom-line mentality of the top management or the supervisors. To meet the bottom line demands and work pressure from the top management on the supervisors to meet those demands well on time leads to the bad attitude of supervisors. Furthermore, this unethical treatment towards employees leads to the social undermining of the employees. The results were drawn on the following quotes from the participants.

\section{A: Not many ethics are followed to meet the bottom- line demands. Feel that we are not treated equally. Natural phenomenon. Being an employee, we have to follow the orders and complete the tasks without con- sidering the ethical or unethical issues as we know the cultural norms that if we don't do the task what will happen. When a task is assigned from top manage- ment, then the HOD makes sure the work is completed. So, the HOD treats the employees harshly/scolds them. The HOD does want the task completed as they have to face the top management. \\ D: Not equal treatment. Yes, not fair treatment when the bottom-line demands are to meet on time and when there is pressure from the top management.}

We have noticed from nearly $85 \%$ of participants that the nature of the task and pressure from top management leads to employees' unethical behavior towards their social undermining. They are not treated equally; sometimes, favoritism is done as one participant mentioned this the favoritism. The majority of the interviewees feel that there is a lack of justice in the organizations. Morally they do not feel strong and just 
do the task assigned to them under any condition. The ethics are only followed depending on the nature of the task, which is a surprising and disturbing fact.

\section{Mapping of Themes}

Figure 1 explains how the themes emerged during the data analysis phase of this research. The two broad themes depicted in the yellow box are the main themes i.e., bottom line mentality and perception and trust of employees. The sub-themes are depicted in the blue boxes.

Bottom line mentality depends upon the nature of the task (green box) which has further two sub themes which are easy task nature and difficult nature of task. The easy nature of task leads towards the good attitude of supervisor while the difficult nature of task lead towards the bad attitude of supervisor. The analysis of data revealed further sub-themes of bad attitude of supervisor. The bad attitude of supervisor lead towards the social undermining of employees (brown box) and the reason of this bad attitude and social undermining of employees is that the ethical leadership is being ignored.
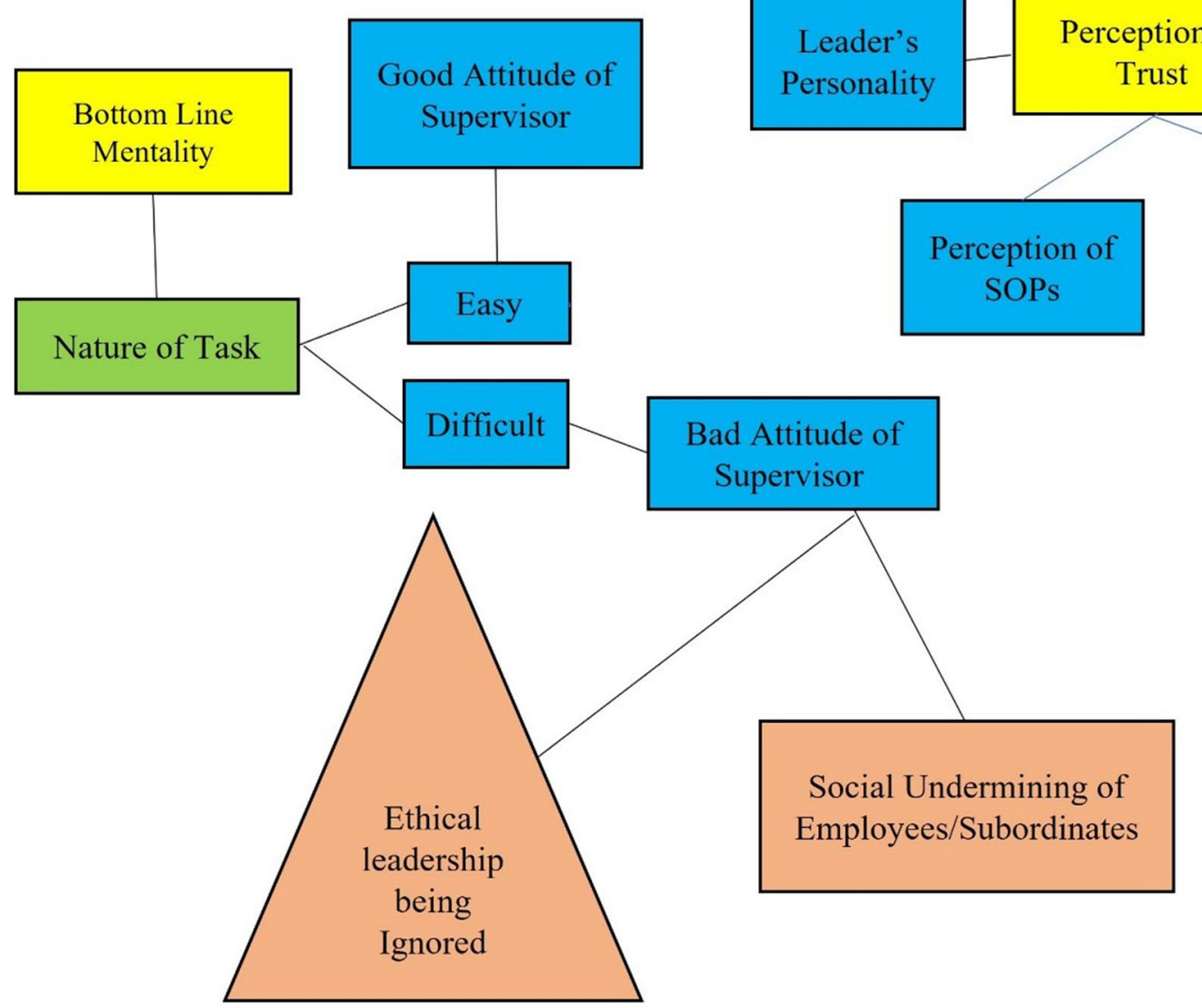

Fig. 1 Mapping of themes Employees/Subordinates
Four sub-themes emerged out of perception and trust of employees. The sub-themes of perception and trust of employees are depicted in blue box which are leader's personality, perception of SOP's, work pressure and abusive behavior.

\section{Discussion}

Based on the analysis of results, the conceptual framework proposed is shown in Fig. 1. The development of the conceptual framework is based on the two broad themes: top management bottom-line mentality and trust and perceptions of followers. Two sub-themes emerge from the bottom-line mentality: the nature of the task and the attitude of the supervisor, while these two have one sub-theme: the social undermining of employees. Supervisors' attitude is linked with ethical leadership (bad attitude of the supervisor to achieve bottom-line demands ignores all ethical practices). The four sub-themes emerge from trust and perception of employees: abusive behavior, leader's personality, perception of Standard Operating Procedures (SOP's), and work pressure, which leads to the emergence of ethical leadership.

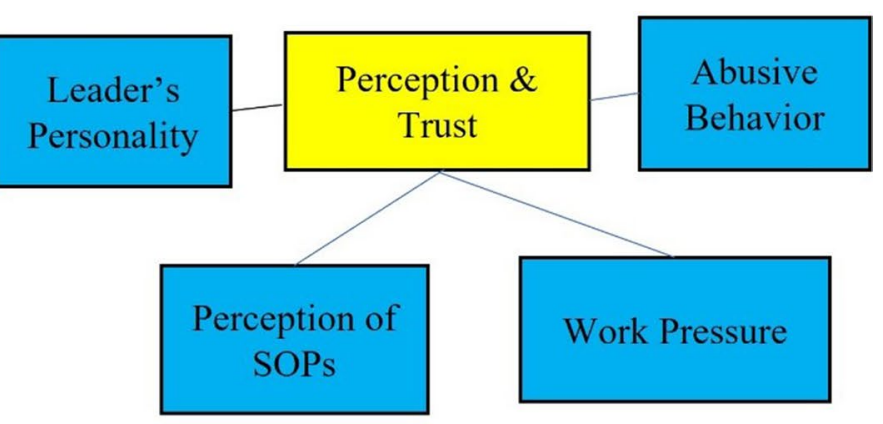


The findings of this research contribute to managers' bottom-line mentality in the organizations of Pakistan and how this led to the ethical leadership behavior and social undermining of the employees. Additionally, it contributes to the trust and perception of followers on their middle-level managers, and immediate supervisors motivate leaders in the emergence of ethical leadership (Fig. 2).

The analysis of data reveals that leaders' personality becomes more important when it comes to the building of followers' perceptions. It has also been observed that when followers build a perception of their leaders that they are good and have a good personality, they automatically believe that they behave ethically (Rousseau et al., 1998; Yang \& Mossholder, 2010). They tend to assume that all the ethical standards and SOPs are being followed by their leaders, even if there is no existence of such procedures (Burke et al., 2007). An analysis of findings from different departments indicated that even supervisors indulge in abusive behavior in the textile industry. One possible reason is the lack of education in manufacturing intense organizations (McCann $\&$ Holt, 2009). As it has been reported that even during their past experiences and in other companies within the industry, the situation is the same. Workers are being bullied, use of abusive language by the supervisors, and making them afraid of getting fired is a general practice.

Employees develop a strong foundation of trust in their supervisors based on their perceptions of their leaders' ethical behavior. However, it has nothing to do with whether leaders are behaving ethically or not. The findings revealed that although there were no formal SOPs, employees still perceived that their supervisors were ethically behaving based on their personality. Therefore, the personality of a leader turns out to be more powerful in building up perceptions of followers about their leaders, and this perception, in turn, would develop a higher level of trust among followers.

The role of top management seems to be complex, as the findings reveal that a top middle manager's ethical behavior depends on the ethical behavior of department heads. In comparison, middle managers' behavior does not depend on their leaders (directors). One possible reason could be a lack of communication. They never get to know the issues at the workers' level, as some of the respondents reported the communication gap. There are no communication channels between lower-level workers and top management. Only the department heads communicate with the top management, and therefore, middle-level managers are never reported to the top management. One of the main reasons could be job security. Employees fear that if they raise their voice against their managers, they will lose their jobs.

To summarize, many respondents even directly mentioned that it is not that their perception would result in them behaving ethically. Hence, we propose that leaders' personality would lead to building perceptions of followers. This perception is strong enough that it does not matter if the leader is behaving ethically. This situation is prominent in the manufacturing sector of developing countries such as Pakistan because of the lower education levels (McCann \& Holt, 2009). The SOPs are not well defined and communicated to employees; therefore, managers and leaders have the freedom to behave and get the job done by any means. Leaders are mainly promoted based on their experience level and not based on education. This entails the abusive behavior of supervisors, which builds a negative perception in the minds of subordinates about their leaders.

Fig. 2 Conceptual framework

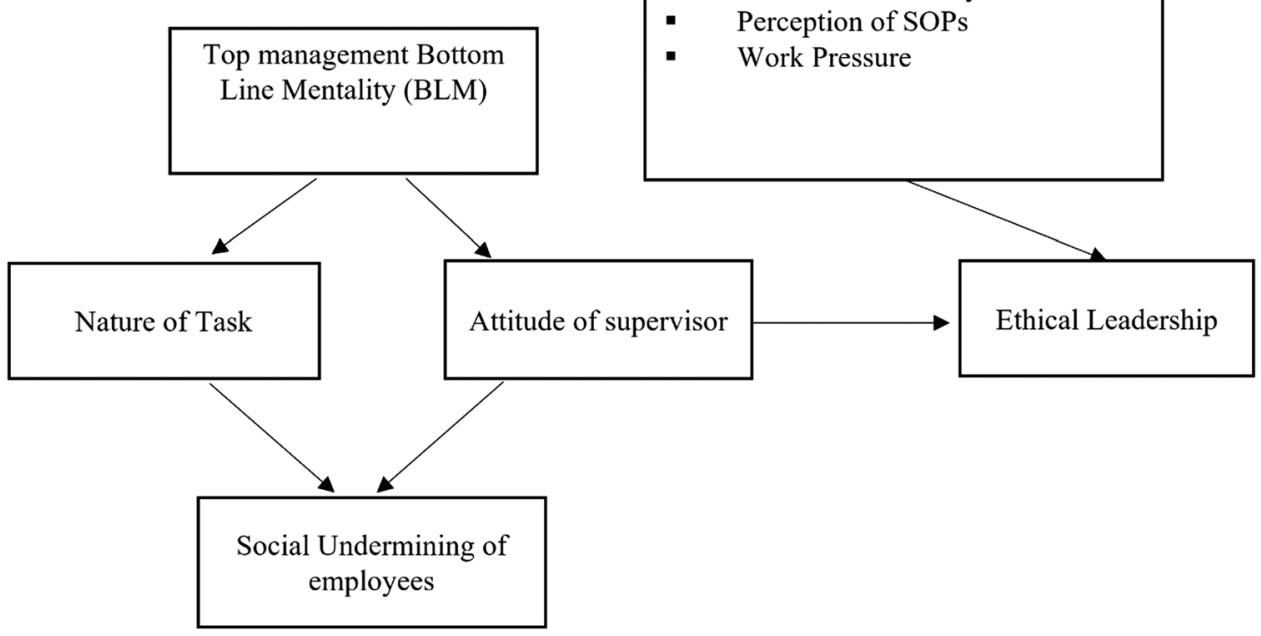


The bottom-line mentality is at its fancy, and there is a significant need to explore this construct in various organizational settings (Greenbaum et al., 2012; Sims \& Brinkman, 2002). This study has covered up the gap with specific reference to conducting this study in Pakistan. In this study, "bottom line mentality" refers to the role of top management in meeting the bottom line demands and how this can lead to the social undermining of employees.

The analysis showed that employees and management sometimes get too involved in achieving the demands of the bottom line that they often forget to follow ethical leadership practices, although ethical considerations are equally important (Greenbaum et al., 2020; Wolfe, 1988). The employees' voice depicted that there is a need for proper ethical leadership in the organizations, and the Standard Operating Procedures should be developed to ensure that all employees are treated equally and ethically.

We have analyzed that to meet the demands, the top management ignores the demands of the employees. The same reference can be found in the literature, which states that the focus of the management is just to increase the profits of the organization (Wolfe, 1988). One of the participants stated in the interview that the employees work hand to meet the organization's demands, and all the rewards are taken over by the managers who are supervising them. It can be concluded here that the bottom-line goals of the organization are being met at the expense of other employees working within the same organization (Sims \& Brinkman, 2002). According to Greenbaum et al. (2012), the success of employees is intentionally hindered by the top management, which leads to social undermining (e.g., providing the wrong information, competition for status, and delaying work, etc.). As per the literature, such practices of management are harmful to the proper functioning of the organization (Greenbaum et al., 2020). For example, management's BLM can lead to the social undermining of (Greenbaum et al., 2012) unethical behavior and abusive behavior. The analysis showed that middle managers have the role of acting ethically and asking their subordinates to follow ethics so that the element of social undermining of the employees can be reduced to zero. This role of middle managers has been highlighted in the literature (Singh et al., 2020). As mentioned by one of the interviewers, their middle managers have a role in this. "Definitely, our middle managers follow the ethics and motivate them to follow the ethics."

\section{Theoretical Implications}

The objective of this study was to explore the trust and perception of followers of their middle-level managers and immediate supervisors on how to motivate leaders in the genesis of ethical leadership and to explore the perceptions of top management's bottom-line mentality and how it can lead to the social undermining of middle-level managers in the genesis of ethical leadership. The gap in the literature to understand individual behavior, bottom-line mentality, trust perceptions, and social undermining from the perspective of ethical leadership was covered in this study in the context of an underdeveloped country, Pakistan.

The study's main findings relate to its objectives, that the personality and positioning of the leader (middle manager and top manager) are more important in building perceptions in the minds of followers. The results of the study revealed that trust has a significant role in maintaining employees' trust, and that bottom-line demands play an important role in the social undermining of employees. To shift the focus towards the personality of leaders, which current literature has been continuously criticizing. Theorists can incorporate more personality models and theories into ethical leadership to create an integrated approach. It turns out that followers' perceptions are more important than leaders' ethical behavior.

The empirical contribution of this study has indicated that employees' interests are taken for granted, and bottom-line objectives are more important in the eyes of top management. This study has opened new directions for the scholars and theorists of the social sciences to investigate the model proposed by this study to determine the role of middle-level managers as they are the key source of reducing the social undermining of their subordinates. The model proposed in this study can be tested to strengthen and generalize the findings of this study for the theoretical expansion of LMX and ethical leadership theory.

\section{Practical Implications}

With regard to the implications for human resource management in respect to ethical leadership, the findings of this research offer some pathways. First, the findings of this research offer organizations an opportunity to invest their resources in the implementation and practice of ethical leadership in their organizations. Secondly, the extant literature has highlighted that the bottom-line mentality of the top management leads towards the dysfunctionality of the organizations. The fulfillment of demands and achievement of higher profits narrow down the role of top management. We have mentioned in our research that such mentality leads to the social undermining of the employees. Thus, we studied this aspect from the qualitative lens by listening directly to the employees about such practices. We have contributed to improving managerial practices by bringing light to this issue by conducting research in a developing country. Thus, the findings of this research recommend that better performance and profit maximization expectations from the employees can be enhanced by reducing the bottomline mentality. Organizations should understand that the 
bottom-line mentality can be both beneficial and costly for employees and organizations. Therefore, it is important to incorporate the findings of our research into managerial programs to make the leaders realize that the bottom-line mentality can lead to the social undermining of employees, thus, as a result, poor performance and hence reduced profits.

Our findings have practical implications for the ethical leadership practices in organizations. The extant literature has focused mainly on the factors contributing to ethical leadership practices. Ethical leadership practices hinder unethical values and practices at the workplace. Our research has studied the phenomenon of ethical leadership and how unethical leadership practices can be a cause of social undermining of employees. The findings contribute to these managerial issues by giving due importance to ethical leadership practices. Managers should keep moral values and ethics in mind while communicating the bottom-line demands to their employees. The findings of this research highlight the significance of following ethics in the organization. The top management should explicitly state in their strategies the significance of ethical leadership practices, and these practices should be followed while meeting the bottom-line demands of the organizations. However, the focal point here to mention is the formulation of policies, rules, and regulations, ethical practices, and the implementation of these ethical practices. This study suggests the pivotal role of ethical leadership in organizations. Additionally, the implementation of such practices should be rewarded and promoted in organizations.

Finally, this study offers useful insights for the top management to get the actual picture in terms of employees' perspectives. The employees' trust perception of top management makes them act ethically and, thus, follow all ethical leadership practices. Our findings suggest that the organization's practitioners avoid abusive behavior to meet the demands of the bottom line. Such demands can be fulfilled by good leadership and by the charismatic personality of the leaders. The top and middle management should devise Standard Operating Procedures (SOP's) and ethical values to lower social undermining and work pressure on the lower-level employees. As a result, the management can win the trust of their employees.

\section{Limitations and Future Research}

The present study has been conducted considering time and other constraints; hence, it has some limitations. The first limitation is the small sample size. A larger sample size could have explored the opinions and viewpoints of more individuals. As we could get only 2 representatives from each department, more representation might have led to more similarities or differences to develop further in-depth knowledge. Moreover, a cross-industry comparison where more manufacturing companies can understand how the leaders specifically behave: consistent with this, future studies can also consider the services sector, especially in the current COVID situation where most of the services industries are operating online, and teams are connected virtually. It will be interesting to know how ethical leadership has evolved or in the process of evolving with employees' perception and trust in their leaders while connecting virtually.

The statistical generalization of qualitative is rather difficult because it is neither about the particular views nor particular location about which the wider applicability of findings can be drawn rather it is the in-depth study of a particular phenomenon, lived experiences and factors that shape the phenomenon being studied (Lewis et al., 2003). The representation generalization of findings does not require how far the findings can be applied to parent population (Lewis et al., 2003). In a traditional sense, the qualitative studies are not generalizable rather they contribute to the community with a more in-depth finding (Myers, 2000).

This research has sought to capture how trust and perception of followers on their middle-level managers and immediate supervisors motivate leaders in the genesis of ethical leadership and how the perceptions of top management's bottom-line mentality led to the social undermining of middle levels managers in the genesis of ethical leadership. While, limited in sample size, our target population was small because negotiating access to the population was slow and labor intensive due to COVID-19 restrictions, therefore we opted for the telephonic interview to reach the right population. Although, limited in sample size but the method opted for data collection helped us to generate the rich data.

Being qualitative in nature, the interviews were opted to establish the in-depth interviews with the respondents and to address the research problem in-depth. The smaller the sample size, the closer is to establish the in-depth relationship with the respondents, therefore, the smaller number of cases has facilitated the researchers to establish the close association with the participants in naturalistic settings. The phenomenon being under study usually occurs once therefore, the sample size is often kept small in qualitative research. The saturation of themes is likely to occur within the first six in-depth interviews and saturation point is clearly evident at 12 interviews (Guest et al., 2006). Additionally, in phenomenology approach the sample size is usually kept small because in the view of Gonzalez (2009), the sample size is driven on the basis of the main variants of the study and once the start appearing the sample size of less than twenty are common. Cresswell (2011) has argued that it is normal "to study a few individuals or a few cases" (pg, 209) in qualitative research studies.

The data saturation was achieved, and same themes were appearing therefore, the authors stopped their data collection 
on 10 interviews. According to qualitative researchers, most of data can be collected from the initial interviews from the participants and sample size of 10 is adequate where the characteristics of the population are homogenous (Sandelowski, 1995).

Hence, the sample size adopted for this research was appropriate as per the scope and the nature of the topic (Morse, 2000). The contact time with each participant was enough to get the richer information Marshall et al. (2013) and in this research the target population was homogenous working in the same industry and at same level (Trotter, 2012). Additionally, as per aims and objectives of this study the target population selected for the sampling was the truly representative (Bock $\&$ Sergeant, 2002).

The philosophical stance of this study is constructivism which requires in-depth inquiry of the matter; thus, this indepth understanding of phenomenon can be achieved through smaller number of interviews from the target population (Boddy, 2016). Albeit, as per qualitative researchers there is no hard and fast rule for the minimum sample size requirement for qualitative research. The minimum sample size for this study is justified within the aim, scope and nature of this study.

The second limitation is related to the informants; data was collected from subordinates to understand their perceptions and trust. However, future studies could include middle management, department heads, and top management along the same lines. As the results indicated, the role of top management is unclear with respect to the head of departments and, ultimately, middle-level managers. Therefore, future studies can also explore trust and perception by considering the viewpoints of middle managers and integrating them with the views of employees at lower levels. Thirdly, data was collected cross-sectionally from employees probing their past experiences. However, this perception and the trust identified in the study are ongoing. Therefore, future studies can consider exploring the evolution of employees' trust and perception of their leaders by collecting data during different time intervals. This perception may evolve as some difficult situations are encountered. It will be interesting to see the evolution and even co-evolution of employees' trust and perception of their leaders. Finally, we recommend and open the floor for new researchers to incorporate other process theories to conduct a grounded theory. Although ethical leadership is not a novel approach, for further theory advancement, a more qualitative approach such as grounded theory can be of great significance.

\section{Conclusion}

Ethical leadership has gained special attention from scholars and researchers during the last decade. In today's dynamic work environment where employees are a competitive advantage, their concerns and issues should be addressed fairly by their leaders. This study signifies the ethical behavior of middle-level managers towards their subordinates and how the followers shape their perception. It has been found that leaders' behavior and personality are more important in building trust and the perception of employees, and this perception does not entail that a leader will act ethically in real life, but they are perceived to be. The findings reported that the bottom-line mentality demands are given priority, and thus to achieve these demands, ethical values are being ignored while the nature of the task and attitude of the supervisor leads towards the social undermining of the employees.

Data Availability The datasets generated during and/or analyzed during the current study are available from the corresponding author on reasonable request.

\section{Declarations}

Ethical Approval All ethical considerations were considered to maintain the anonymity and confidentiality of data.

Consent to Participate Prior consent of all participants, included in this study, was obtained.

Conflict of Interests There is no competing interest to declare.

\section{References}

Aggarwal, A., Chand, P. K., Jhamb, D., \& Mittal, A. (2020). Leadermember exchange, work engagement, and psychological withdrawal behavior: The mediating role of psychological empowerment. Frontiers in Psychology, 11, 423.

Ahn, J., Lee, S., \& Yun, S. (2018). Leaders' core self-evaluation, ethical leadership, and employees' job performance: The moderating role of employees' exchange ideology. Journal of Business Ethics, 148(2), 457-470.

Andersen, I., Buch, R., \& Kuvaas, B. (2020). A Literature Review of Social and Economic Leader-Member Exchange. Frontiers in Psychology, 11, 1474.

Babalola, M. T., Bligh, M. C., Ogunfowora, B., Guo, L., \& Garba, O. A. (2019). The mind is willing, but the situation constrains: Why and when leader conscientiousness relates to ethical leadership. Journal of Business Ethics, 155(1), 75-89.

Babalola, M. T., Greenbaum, R. L., Amarnani, R. K., Shoss, M. K., Deng, Y., Garba, O. A., \& Guo, L. (2020). A business frame perspective on why perceptions of top management's bottom-line mentality result in employees' good and bad behaviors. Personnel Psychology, 73(1), 19-41.

Bahadori, M., Ghasemi, M., Hasanpoor, E., Hosseini, S. M., \& Alimohammadzadeh, K. (2021). The influence of ethical leadership on the organizational commitment in fire organizations. International Journal of Ethics and Systems.

Bandura, A. (1986). Social foundation of thought and action. In: Englewood cliffs, NJ: prentice Hall.

Bandura, A., \& Walters, R. H. (1977). Social learning theory (Vol. 1): Englewood cliffs Prentice Hall. 
Banks, G. C., Fischer, T., Gooty, J., \& Stock, G. (2021). Ethical leadership: Mapping the terrain for concept cleanup and a future research agenda. The Leadership Quarterly, 32(2), 101471.

Blau, P. (1964). 1964 Exchange and power in social life. Wiley.

Bock, T., \& Sergeant, J. (2002). Small sample market research. International Journal of Market Research, 44(2), 1-7.

Bougie, R., \& Sekaran, U. (2016). Research Methods for Business: A Skill Building 7 ed: Wily.

Brown, M. E., \& Treviño, L. K. (2006). Ethical leadership: A review and future directions. The Leadership Quarterly, 17(6), 595-616.

Brown, M. E., Treviño, L. K., \& Harrison, D. A. (2005). Ethical leadership: A social learning perspective for construct development and testing. Organizational Behavior and Human Decision Processes, 97(2), 117-134.

Buengeler, C., Piccolo, R. F., \& Locklear, L. R. (2021). LMX differentiation and group outcomes: A framework and review drawing on group diversity insights. Journal of Management, 47(1), 260-287.

Burke, C. S., Sims, D. E., Lazzara, E. H., \& Salas, E. (2007). Trust in leadership: A multi-level review and integration. The Leadership Quarterly, 18(6), 606-632.

Byun, G., Dai, Y., Lee, S., \& Kang, S. (2017). Leader trust, competence, LMX, and member performance: A moderated mediation framework. Psychological Reports, 120(6), 1137-1159.

Chen, H. L., \& Lin, Y. L. (2018). Goal orientations, leader-leader exchange, trust, and the outcomes of project performance. International Journal of Project Management, 36(5), 716-729.

Cheng, J., Bai, H., \& Yang, X. (2019). Ethical leadership and internal whistleblowing: A mediated moderation model. Journal of Business Ethics, 155(1), 115-130.

Chong, E., \& Wolf, H. (2010). Factors influencing followers' perception of organisational leaders. Leadership \& Organization Development Journal.

Creswell, J. (2003). Mixed methods approaches. Research design: Qualitative, quantitative, and mixed methods approaches, 208-227.

Gasiorowska, A., Chaplin, L. N., Zaleskiewicz, T., Wygrab, S., \& Vohs, K. D. (2016). Money cues increase agency and decrease prosociality among children: Early signs of market-mode behaviors. Psychological Science, 27(3), 331-344.

Gaudet, M.-C., \& Tremblay, M. (2017). Initiating structure leadership and employee behaviors: The role of perceived organizational support, affective commitment and leader-member exchange. European Management Journal, 35(5), 663-675.

Gonzalez, C. (2009). Conceptions of, and Approaches to, Teaching Online: A Study of Lecturers Teaching Postgraduate Distance Courses. Higher Education, Springer, 57(3), 299-314.

Gottfredson, R. K., Wright, S. L., \& Heaphy, E. D. (2020). A critique of the Leader-Member Exchange construct: Back to square one. The Leadership Quarterly, 31(6), 101385.

Greenbaum, R. L., Babalola, M., Quade, M. J., Guo, L., \& Kim, Y. C. (2020). Moral burden of bottom-line pursuits: How and when perceptions of top management bottom-line mentality inhibit supervisors' ethical leadership practices. Journal of Business Ethics, 1-15.

Greenbaum, R. L., Mawritz, M. B., \& Eissa, G. (2012). Bottom-line mentality as an antecedent of social undermining and the moderating roles of core self-evaluations and conscientiousness. Journal of Applied Psychology, 97(2), 343.

Guest, G., Bunce, A., \& Johnson, L. (2006). How many interviews are enough? An experiment with data saturation and variability. Field Methods, 18(1), 59-82.

Hayllar, B., \& Griffin, T. (2005). The precinct experience: A phenomenological approach. Tourism Management, 26(4), 517-528.

Henderson, M., \& Argyle, M. (1986). The informal rules of working relationships. Journal of Organizational Behavior, 7(4), 259-275.
Herman, H., Troth, A. C., Ashkanasy, N. M., \& Collins, A. L. (2018). Affect and leader-member exchange in the new millennium: A state-of-art review and guiding framework. The Leadership Quarterly, 29(1), 135-149.

Kalshoven, K., Den Hartog, D. N., \& De Hoogh, A. H. (2011). Ethical leadership at work questionnaire (ELW): Development and validation of a multidimensional measure. The Leadership Quarterly, 22(1), 51-69.

Khan, A. A., \& Khan, M. (2010). Pakistan textile industry facing new challenges. Research Journal of International Studies, 14(14), 21-29.

Le, B. P., \& Tran, Q. T. (2020). Leadership practice for building trust of followers: Decisive factors of organizational performance. SEISENSE Journal of Management, 3(2), 45-57.

Lemoine, G. J., Hartnell, C. A., \& Leroy, H. (2019). Taking stock of moral approaches to leadership: An integrative review of ethical, authentic, and servant leadership. Academy of Management Annals, 13(1), 148-187.

Lewis, J., Ritchie, J., Ormston, R., \& Morrell, G. (2003). Generalising from qualitative research. Qualitative Research Practice: A Guide for Social Science Students and Researchers, 2, 347-362.

Li, C. (2013). Ethical leadership in firms: Antecedents and consequences. The University of Alabama,

Lloyd, K. J., Boer, D., \& Voelpel, S. C. (2017). From listening to leading: Toward an understanding of supervisor listening within the framework of leader-member exchange theory. International Journal of Business Communication, 54(4), 431-451.

Lusher, D., Robins, G., Pattison, P. E., \& Lomi, A. (2012). "Trust Me": Differences in expressed and perceived trust relations in an organization. Social Networks, 34(4), 410-424.

Maak, T., Pless, N. M., \& Voegtlin, C. (2016). Business statesman or shareholder advocate? CEO responsible leadership styles and the micro-foundations of political CSR. Journal of Management Studies, 53(3), 463-493.

Mahsud, R., Yukl, G., \& Prussia, G. (2010). Leader empathy, ethical leadership, and relations-oriented behaviors as antecedents of leader-member exchange quality. Journal of Managerial Psychology.

Malterud, K., Siersma, V. D., \& Guassora, A. D. (2016). Sample size in qualitative interview studies: Guided by information power. Qualitative Health Research, 26(13), 1753-1760.

Mark, S., Philip, L., \& Adrian, T. (2009). Research methods for business students. In: Prentice Hall.

Marquardt, D. J., Casper, W. J., \& Kuenzi, M. (2020). Leader Goal Orientation and Ethical Leadership: A Socio-Cognitive Approach of the Impact of Leader Goal-Oriented Behavior on Employee Unethical Behavior. Journal of Business Ethics, 1-17.

Marshall, B., Cardon, P., Poddar, A., \& Fontenot, R. (2013). Does sample size matter in qualitative research?: A review of qualitative interviews in IS research. Journal of Computer Information Systems, 54(1), 11-22.

Mawritz, M. B., Greenbaum, R. L., Butts, M. M., \& Graham, K. A. (2017). I just can't control myself: A self-regulation perspective on the abuse of deviant employees. Academy of Management Journal, 60(4), 1482-1503.

McCann, J., \& Holt, R. (2009). Ethical leadership and organizations: An analysis of leadership in the manufacturing industry based on the perceived leadership integrity scale. Journal of Business Ethics, 87(2), 211-220.

Mesdaghinia, S., Rawat, A., \& Nadavulakere, S. (2019). Why moral followers quit: Examining the role of leader bottom-line mentality and unethical pro-leader behavior. Journal of Business Ethics, 159(2), 491-505.

Mo, S., \& Shi, J. (2017). Linking ethical leadership to employees' organizational citizenship behavior: Testing the multilevel 
mediation role of organizational concern. Journal of Business Ethics, 141(1), 151-162.

Molinsky, A. L., Grant, A. M., \& Margolis, J. D. (2012). The bedside manner of homo economicus: How and why priming an economic schema reduces compassion. Organizational Behavior and Human Decision Processes, 119(1), 27-37.

Morse, J. M. (2000). Determining sample size. In: Sage Publications Sage CA: Thousand Oaks, CA.

Mostafa, A. M. S., Farley, S., \& Zaharie, M. (2020). Examining the boundaries of ethical leadership: the harmful effect of Co-worker social undermining on disengagement and employee attitudes. Journal of Business Ethics, 1-14.

Moustakas, C. (1994). Phenomenological research: Analyses and examples. Phenomenological research methods, 120-154.

Myers, M. (2000). Qualitative research and the generalizability question: Standing firm with Proteus. The Qualitative Report, 4(3), 9.

Peng, A. C., \& Kim, D. (2020). A meta-analytic test of the differential pathways linking ethical leadership to normative conduct. Journal of Organizational Behavior, 41(4), 348-368.

Piccolo, R. F., Greenbaum, R., Hartog, D. N., \& d., \& Folger, R. (2010). The relationship between ethical leadership and core job characteristics. Journal of Organizational Behavior, 31(2-3), 259-278.

Prastio, D., Indradewa, R., \& Syah, T. Y. R. (2020). Ethical Leadership Effect Trust in Leader, Work Engagement and Burnout Over Turnover Intension. Journal of Multidisciplinary Academic, 4(5), 283-288.

Rousseau, D. M., Sitkin, S. B., Burt, R. S., \& Camerer, C. (1998). Not so different after all: A cross-discipline view of trust. Academy of Management Review, 23(3), 393-404.

Sandelowski, M. (1995). Sample size in qualitative research. Research in Nursing \& Health, 18(2), 179-183.

Saunders, M., Lewis, P., \& Thornhill, A. (2009). Research methods for business students: Pearson education.

Setyaningrum, R. P., Setiawan, M., \& Irawanto, D. W. (2020). Servant Leadership Characteristics, Organisational Commitment, Followers' Trust, Employees' Performance Outcomes: A Literature Review. European Research Studies, 23(4), 902-911.

Simons, T. (2002). Behavioral integrity: The perceived alignment between managers' words and deeds as a research focus. Organization Science, 13(1), 18-35.

Sims, R. R., \& Brinkman, J. (2002). Leaders as moral role models: The case of John Gutfreund at Salomon Brothers. Journal of Business Ethics, 35(4), 327-339.
Singh, A., Klarner, P., \& Hess, T. (2020). How do chief digital officers pursue digital transformation activities? The role of organization design parameters. Long Range Planning, 53(3), 101890.

Sirola, N., \& Pitesa, M. (2017). Economic downturns undermine workplace helping by promoting a zero-sum construal of success. Academy of Management Journal, 60(4), 1339-1359.

Solinger, O. N., Jansen, P. G., \& Cornelissen, J. P. (2020). The emergence of moral leadership. Academy of Management Review, 45(3), 504-527.

Treviño, L. K., Weaver, G. R., \& Reynolds, S. J. (2006). Behavioral ethics in organizations: A review. Journal of Management, 32(6), 951-990.

Trotter, R. T., II. (2012). Qualitative research sample design and sample size: Resolving and unresolved issues and inferential imperatives. Preventive Medicine, 55(5), 398-400.

Valle, M., Kacmar, K. M., Zivnuska, S., \& Harting, T. (2019). Abusive supervision, leader-member exchange, and moral disengagement: A moderated-mediation model of organizational deviance. The Journal of Social Psychology, 159(3), 299-312.

Wolfe, D. M. (1988). Is there integrity in the bottom line: Managing obstacles to executive integrity.

Yang, J., \& Mossholder, K. W. (2010). Examining the effects of trust in leaders: A bases-and-foci approach. The Leadership Quarterly, 21(1), 50-63.

Yu, M.-C., Mai, Q., Tsai, S.-B., \& Dai, Y. (2018). An empirical study on the organizational trust, employee-organization relationship and innovative behavior from the integrated perspective of social exchange and organizational sustainability. Sustainability, 10(3), 864.

Zhu, W., Zheng, X., He, H., Wang, G., \& Zhang, X. (2019). Ethical leadership with both "moral person" and "moral manager" aspects: Scale development and cross-cultural validation. Journal of Business Ethics, 158(2), 547-565.

Zoghbi-Manrique-de-Lara, P., \& Viera-Armas, M. (2019). Does ethical leadership motivate followers to participate in delivering compassion? Journal of Business Ethics, 154(1), 195-210.

Publisher's Note Springer Nature remains neutral with regard to jurisdictional claims in published maps and institutional affiliations. 